\title{
O CORPO SAGRADO DA MONARQUIA VISIGODA
}

ANDRADE FILHO, Ruy de Oliveira. Imagem e reflexo. Religiosidade e Monarquia no Reino Visigodo de Toledo (séculos VI-VIII). São Paulo: Edusp, 2012.

Marcus Cruz ${ }^{1}$

(recebido em 14/05/2013, aprovado em 10/02/2013)

O campo historiográfico brasileiro atravessou, nas últimas décadas, um amplo e profundo processo de consolidação e expansão. Essa dinâmica, amparada fortemente no crescimento do ensino superior no país, tanto em cursos de graduação e principalmente na pós-graduação, cria as condições para que a historiografia nacional avançasse em termos teóricos e metodológicos, mas também ultrapassasse as fronteiras temáticas que tradicionalmente limitavam os estudos históricos.

No bojo deste processo assistimos senão a emergência, mas com certeza 0 estabelecimento e a consolidação dos estudos históricos voltados para temáticas vinculadas a Antiguidade e o Medievo. As dissertações de mestrado, as teses de doutorado, artigos e livros se multiplicaram, ainda que aquém do desejável, abordando uma vasta gama de questões que se debruçam desde aos problemas da economia mesopotâmica até a santidade na realeza portuguesa no alvorecer da modernidade.

Ruy de Oliveira Andrade Filho, professor da Universidade Estadual Paulista Julio de Mesquita do campus de Assis, se insere neste processo com especial destaque uma vez que realizou sua formação acadêmica neste esforço de estabelecimento e consolidação dos estudos antigos e medievais no Brasil e posteriormente passa, ele próprio, a formar novos historiadores voltados para essas temáticas. Além de contribuir para o desenvolvimento desta historiografia com uma densa e expressiva produção bibliográfica composta de diversos artigos publicados em revistas nacionais e internacionais, capítulos de livros e livros.

Imagem e reflexo. Religiosidade e Monarquia no Reino Visigodo de Toledo (Séculos VI-VIII) é a mais recente obra lançada pelo Professor Ruy Andrade Filho. $O$ livro publicado no ano de 2012 é fruto da tese de doutoramento do autor defendida em 1997 na Universidade de São Paulo. A larga distância temporal entre a defesa da tese e a sua publicação na forma de livro é um sintoma

Prof. Adjunto da Universidade Federal de Mato Grosso. Fundador do VIVARIUM ï Laboratório de Estudos da Antiguidade e Medievo. 
bastante significativo da lógica do mercado editorial brasileiro e da política de publicação das editoras universitárias nacionais.

Neste livro o Professor Ruy Andrade Filho se propõe analisar as articulações entre religiosidade e a montagem da monarquia católica visigoda, após a conversão de Recaredo, primeiro monarca visigodo a adotar o cristianismo niceciano, abandonando assim a fides gothorum, ou seja o cristianismo ariano. Nas palavras do autor: "Nossa proposta apresenta dois elementos: religiosidade e Monarquia. Nosso objeto é a análise das relações desses dois elementos entre meados do século VI e início do século VIII, ou seja: da conversão do reino de Toledo à sua destruição."2

Esta proposta analítica esta assentada numa sólida base documental com uma variada tipologia, desde testemunhos de cunho legal passando pelas fontes hagiográficas, doutrinais, conciliares, literárias entre outras chamadas ao debate no intuito de discutir a problemática colocada. Ainda sobre a questão documental o autor se posiciona no debate acerca da quantidade e da qualidade das fontes para o estudo da Península Ibérica na Antiguidade Tardia. A resposta é firme e nos parece absolutamente correta: "...acreditamos que, como noutras partes do ocidente da Antiguidade Tardia, a documentação da península é muito lacunar, mas não chega a constituir uma exceção. parece-nos que o problema reside mais no método do que nos tipos de evidência disponiveis"3

Imagem e reflexo, por sua abordagem teórica, se constitui como um exercício de história das mentalidades dentro de uma perspectiva, que na medievalística brasileira foi praticada e teorizada por Hilário Franco Junior, em que sem abandonar a concepção de Jacques Le Goff em que a mentalidade se define como um elemento que perpassa todos os integrantes de uma sociedade, percebe tanto a existência de polos nesta mentalidade quanto de uma "cultura intermediária", ponto de interseção entre esses polos.

O conceito de "cultura intermediária" é essencial nas discussões no primeiro capítulo em que se aborda a cristianização da Península Ibérica durante a Antiguidade Tardia. Após chamar a atenção para a diversidade existente na região, especialmente no que tange aos processos de romanização e cristianização como afirma o autor; "...deparamos, grosso modo, com pelo menos duas

\footnotetext{
2 ANDRADE FILHO, Ruy de Oliveira. Imagem e reflexo. Religiosidade e Monarquia no Reino Visigodo de Toledo (séculos VI-VIII). São Paulo: Edusp, 2012. p.30

3 ANDRADE FILHO, Ruy de Oliveira. op.cit. p.29
} 
Hispânias: uma meridional, em que predomina o modo de vida mediterrânico; outra setentrional, na qual a sobrevivência dos modos de vida e de organização social pré-romanos parecem ter sido particularmente mais resistentes à integração com as forças romanas"4. O professor Ruy Andrade Filho passa, então, a discutir a questão central deste capítulo, qual seja a presença de práticas pagãs na Península Ibérica e as estratégias e ações com que a hierarquia eclesiástica buscou enfrentar e enquadrar tais práticas que se inserem numa religiosidade popular que cresce de importância numa sociedade que se ruraliza.

O enquadramento de toda e qualquer manifestação discordante da doutrina defendida pela hierarquia eclesiástica, seja as práticas pagãs ou presença judaica ou ainda a contestação herética, era de fundamental importância para a articulação entre a Igreja e a monarquia visigoda, pois era necessário o estabelecimento de um cristianismo sob a égide dos bispos para servir de fundamento e sustentáculo do poder monárquico.

É exatamente a constituição deste cristianismo episcopal que será discutido no segundo capítulo de Imagem e reflexo que se inicia com as seguintes palavras: "A partir da conversão e da elaboração da Monarquia cristã, supôs-se a composição do reino visigodo de Toledo como um corpo unitário, coeso por uma fé e regido por uma cabeça cuja autoridade provinha do próprio Deus. Desa forma, nele se teria contituído uma verdadeira societas fidelium Christi' 5

Nesta tentativa o clero hispano-visigodo teve que enfrentar a pressão cultural advinda da emergência do mundo rural, deste enfrentamento surge um universo simbólico novo que substituiu 0 anterior marcado pelo realismo pagão e que é atravessado por duas clivagens essenciais clérigo/laico e poderosos/humildes.

A cristianização do campo e dos seus habitantes na sociedade em pleno processo de ruralização é o maior desafio da hierarquia eclesiástica hispano-romana entre os séculos VI e VIII. No esforço de cristianização dos espaços rurais a Igreja procurava: "...evitar confrontos por ações violentas, viabilizando-se assim a substituição ou desnaturalização, das antigas práticas. Nesses procedimentos articulavam-se diversas relações e interpretações recíprocas entre a 'religiosidade popular' e a oficial...Não se tratava simplesmente de aculturação de um resultado da coexistência de duas culturas diferenciadas que interagiam, mas de um sincretismo, entendido 'como um processo

ANDRADE FILHO, Ruy de Oliveira. op.cit. p.39

ANDRADE FILHO, Ruy de Oliveira. op.cit. p.71 
contra-aculturativo implicando manipulações de mitos, empréstimos de ritos, associação de símbolos, às vezes inversão semântica e reintrepretação da mensagem crística"”

Ruy Andrade Filho interpreta, portanto, esse processo a partir de uma dinâmica de caráter sincrética entre dois polos culturais, um denominado de religiosidade popular e outro de religiosidade oficial. A complexa discussão acerca destes conceitos, especialmente ao concernente a religiosidade popular constitui o cerne o capítulo III, intitulado Religiosidade ou religiosidades?

O autor pensa o conceito de religiosidade articulado ao de mentalidade, por isso descarta a possibilidade de entender a religiosidade popular como o resultado do confronto entre cristianismo e paganismo: "A religiosidade não nasce do confronto com o cristianismo, mas emerge dele"6. Da mesma forma considera ser uma análise empobrecedora vincular unicamente as permanências pagãs da religiosidade popular as resistências e as condições socioeconômicas. Por outro lado, também descarta a tese de que as manifestações religiosas dos segmentos mais humildes estaria vinculado ao seu inato desejo de libertação e promoção social.

Na religiosidade popular na Hispânia visigoda as permanências de práticas pagãs não se constituíam como uma mera sobrevivência ou resistência, mas se integravam em um universo simbólico comum, pertencem a uma mentalidade. Por isso observamos a assimilação de mitos e ritos pagãos pela teoria cristã e a aquisição pelos santos de muitas das características de deuses e heróis clássicos ou mesmo pré-romanos. Nas palavras do autor: "...o paganismo foi um fato normal e habitual na península durante o reino visigodo, tal como no restante do Ocidente, sem estar restrito apenas a algumas áreas ou grupos sociais."7

No entanto, com a conversão de Recaredo em 589, o catolicismo passa a ser 0 fundamento ideológico do reino visigodo de Toledo. A discussão da construção dos alicerces de legitimação da autoridade e do poder régio que Ruy Andrade Filho denomina de utopia monárquica acontece fundamentalmente a nos dois capítulos finais da obra.

A ideia central no tocante ao fundamento ideológico da monarquia visigoda após a conversão de Recaredo é uma concepção antropomórfica da realidade na qual a realeza supervisiona e dirige todos os aspectos da sociedade pois o rei "como cabeça de uma comunidade cristã,

$6 \quad$ ANDRADE FILHO, Ruy de Oliveira. op.cit. p.107

ANDRADE FILHO, Ruy de Oliveira. op.cit. p.120 
responsável pela salus de seus membros e com a obrigação de dar conta a Deus do bem-estar da lgreja"8

Esta concepção eliminava qualquer divergência entre a Igreja e a monarquia, esta aliança se consubstanciava na atividade legislativa dos reis na qual aos objetivos práticos eram acrescentadas as finalidades religiosas. Por outro lado a escolha do monarca pelo princípio da Gratia Dei garantia ao monarca não apenas uma legitimação sagrada, mas também que qualquer infidelitas dos súditos se constituía em um crime contra a própria divindade.

Na utopia da monarquia visigoda a religião assumia a função de elementos central de coesão da sociedade, a partir de uma concepção antropormófica do corpo social, cuja a sofisticada teorização encerrava uma dualidade corpo/alma - Monarquia/lgreja, além de possibilitar, na ausência do princípio hereditário no pensamento político visigodo, a invenção de uma genealogia santa dos reis. Nas palavras do autor: "A tentativa de sacralização monárquica e concepção da analogia antropormórfica buscaram criar bases teóricas, políticas e sociais mais seguras paea a estabilização monárquica por via do cristianismo."9 Por outro lado, ainda segundo Ruy Andrade Filho: "A utopia antropomórfica constitui uma tentativa de aproximação com essa religiosidade, estabelecendo correspondência entre o homem (microcosmo) e o mundo(macrocosmo) no qual transitava. quando não pusesse em risco os dogmas da fé, procedimentos da desnaturação e obliteração eram elaborados na religiosidade partilhada, reforçando a presença do sagrado no cotidiano social"10

Após essa apresentação sucinta das principais discussões presente em Imagem e reflexo. Religiosidade e Monarquia no Reino Visigodo de Toledo (séculos VI-VIII) do Professor Ruy Andrade Filho só podemos concluir reafirmando a sólida erudição do autor na argumentação de suas propostas analíticas ancorada em um impressionante conjunto documental demonstrando a consolidação dos estudos antigos e medievais no campo historiográfico brasileiro. Esta é uma obra que incentiva a discussão e o debate por apresentar chaves interpretativas polemicas para questões centrais no âmbito da Antiguidade Tardia e que portanto se constitui como uma contribuição de grande porte e valor para os estudos tardo-antigos.

\footnotetext{
$8 \quad$ ANDRADE FILHO, Ruy de Oliveira. op.cit. p.87

$9 \quad$ ANDRADE FILHO, Ruy de Oliveira. op.cit. p.196

10 ANDRADE FILHO, Ruy de Oliveira. idem. ibidem.
} 